British Journal of Education, Society \&
Behavioural Science
$12(1): \begin{gathered}1-13,2016, \text { Article no.BJESBS.20703 } \\ \text { ISSN: 2278-0998 }\end{gathered}$
SCIENCEDOMAIN international
www.sciencedomain.org

\title{
Developing Interactions between Language and Motor Skills in the First Three Years of Formal Handwriting Education
}

\author{
Ida M. Bosga-Stork ${ }^{1,2^{\star}}$, Jurjen Bosga ${ }^{3,4}$, Jules L. Ellis ${ }^{5}$ \\ and Ruud G. J. Meulenbroek ${ }^{4}$ \\ ${ }^{1}$ Praktijk Kinderfysiotherapie Heuvelrug \& Vallei, De Beaufortweg 18, 3941 PB Doorn, \\ The Netherlands. \\ ${ }^{2}$ Expertisecentum Uniek, Willem van Oranjeschool, Woudenberg, The Netherlands. \\ ${ }^{3}$ Praktijk Bosga-Stork, De Beaufortweg 18, 3941 PB Doorn, The Netherlands. \\ ${ }^{4}$ Radboud University Nijmegen, Donders Institute for Brain, Cognition and Behaviour - Centre for \\ Cognition, P.O.Box 9140, 6500, HE Nijmegen, The Netherlands. \\ ${ }^{5}$ Radboud University Nijmegen, Behavioural Science Institute, P.O.Box 9104, 6500 HE Nijmegen,
}

The Netherlands.

Authors' contributions

This work was carried out in collaboration between all authors. Authors IMBS, JB and RGJM Designed the study, wrote the protocol and supervised the work. Authors IMBS, JB and JLE carried out all laboratories work and performed the statistical analysis. Author JLE managed the analyses of the study. Author IMBS wrote the first draft of the manuscript. Author IMBS managed the literature searches and authors JLE and RGJM edited the manuscript. All authors read and approved the final manuscript.

Article Information

DOI: 10.9734/BJESBS/2016/20703

Editor(s)

(1) Eleni Griva, University of Western Macedonia, Greece. Reviewers:

(1) Sarminah Samad, Universiti Teknologi Mara, Malaysia

(2) Nalini Arumugam, Universiti Teknologi Mara, Malaysia. Complete Peer review History: http://sciencedomain.org/review-history/11536

Original Research Article

Received $5^{\text {th }}$ August 2015

Accepted $25^{\text {th }}$ August 2015

Published 24 ${ }^{\text {th }}$ September 2015

\section{ABSTRACT}

Aims: The present study was designed to provide a basis for teachers and therapists to better understand primary school children's handwriting problems in the face of the complex relationships that exist between literacy skills with the goal to contribute to treatment choices. 
Study Design: A longitudinal, experimental study of handwriting-, literacy- and motor skill development of primary school children.

Place and Duration of Study: Two parallel classrooms of a mainstream medium-sized primary school in the Netherlands participated, covering the first three years of handwriting education.

Methodology: General performances and intercorrelations between developing spelling, reading and handwriting skills were assessed for 32 children (15 girls and 17 boys). A standardized handwriting assessment scale was used to measure handwriting speed performance, a nonlinguistic loop-writing task, using an electronic inking pen and a digitizer evaluated motor performance. Reading- and spelling performance was extracted from a national, school-based follow-up system, used by teachers.

Results: At group level the results showed an increase in performance for all measures, the performance of the children showed considerable variation. Spelling and reading were positively related within all grades $(P=.004 ; .000$ and .005 respectively). Handwriting and reading were positively related within Grade 1 only $(P=.003)$, handwriting and spelling were positively related in Grades 1 and 2 ( $P=.004$ and .001 respectively). The amplitude errors in loop-writing were negatively related to both language measures in Grade 1 (for reading $P=.007$, for spelling $P=.004$ ) Conclusion: To broaden the view on developing handwriting problems in individual primary school children, it is advised to assess spelling and reading skills as well as motor skills, especially in the second and third grade.

Keywords: Handwriting development; handwriting education; language development; motor performance; primary school children.

\section{INTRODUCTION}

Handwriting is a complex skill, the mastering of which requires several years of formal instruction. About 6 - $27 \%$ of typically developing children are reported to experience serious problems in handwriting acquisition where the incidence reported depends on the assessment choices concerning grade and methods [1-6]. The results of handwriting education, usually offered in the first three years of primary school, depend, among other matters, upon the proper and timely development and integration of perceptual, language, and motor capacities [715], but each of these cognitive functions is known to develop at its specific rate and with substantial interindividual differences. For example, the perceptual skills of distinguishing and linking sounds to symbols develop at an earlier age than the fine motor skills that produce them $[9,16]$. Also when starting school, stages of maturity differ and not every child is endowed with the same talent and experience [3]. To provide primary school teachers and therapists with knowledge to help recognize and understand poor handwriting development in the face of the complexity of literacy skills developing at a different rate, more insight into the relationship between these skills in primary school children is needed.

Over the years several models have been proposed to describe handwriting processes in relation to other literacy skills. Research based on the educational models of handwriting and writing development has highlighted the importance of the underlying cognitive processes. These models matured against a background of educational research [8,10,11,14,17]. Juel, Griffith and Gough's 'Simple View' of reading and writing [17] was based on a longitudinal study showing that spelling was the most important factor that defined writing performance in first grade. In 2000, Berninger extended the 'Simple View' towards a model of four functional language systems (language by hand, by ear, mouth and by eye) that develop independently, but are interconnected. Here, handwriting and spelling are seen as 'lower-level' transcription skills, whereas text generation and executive functions are considered 'higher-level' cognitive skills $[7,18]$. As in Juel's 'Simple View', letter and word production are most important in the early stages of handwriting development, until these processes become automated. A related model is the psycholinguistic model of handwriting by Van Galen [19], which differentiated several processes involved in handwriting, each process working on a different time scale (activations of intentions, semantic retrieval, syntactical construction, spelling, allograph selection, size control, and muscular adjustment). As opposed to the models by Berninger and Juel, the model by Van Galen, which is most refined in differentiating processes involved in handwriting, 
has not been applied to handwriting development. Cross-sectional research [20] indicated that handwriting speed increased over the grades. In their longitudinal study Karlsdottir and Stefansson [3] proposed that dysfunction of handwriting speed (4\% of their research group) could be explained as a dysfunction due to handwriting quality, while in their longitudinal study, Hamstra-Bletz \& Blöte [21] found a strong relation for speed and grade. These studies did not take other literacy skills into account. Taken together, the models and studies suggest that the development of handwriting skill in children aged 7 to 9 primarily depends on the gradual automatization of "lower-level" fine motor, spelling and reading skills. Only when attained to a sufficient level, this generates capacity for mental processes at the higher levels of finding words, phrases and meanings [19,22].

The aim of the present study was to widen the perspective on handwriting skill development in relation to the development of literacy and motor skills in Grades 1, 2 and 3. To this end we designed an exploratory, longitudinal study of handwriting acquisition in which we studied the developing relations between literacy and finemotor skills during the first three years of primary school. In order to combine educational progress in reading and writing with motor related handwriting tasks, an existing school-based tracking system for literacy and a known handwriting assessment task were used. Furthermore, we introduced a fine-motor loopwriting task that put pressure on children's capacities to combine spatial and temporal skills that are expected of children in order to write legibly as well as fast enough. Adopting a longitudinal approach highlighted development. Whereas the majority of studies on handwriting acquisition have used cross-sectional designs, the present study concerned 32 primary school children who were first assessed in Grade 1, and then re-examined in Grades 2 and 3.

Our study addressed three questions. The first question concerned the children's language, handwriting and fine-motor loop-writing performance levels in the first three years of primary school. Which performance levels did our participants attain in Grades 1,2 and 3? The answer to the first question provided the baseline against which questions concerning developing skill interactions could be formulated. The second question concerned the developing relations between language, fine motor skills and handwriting acquisition. Do spelling, reading and loop-writing skills contribute to handwriting acquisition similarly in each grade or are certain combinations stronger in one grade than in another grade? The final explorative question was whether assessments of handwriting performance, reading skills, and fine-motor skills contribute to our understanding of handwriting problems.

\section{MATERIALS AND METHODS}

\subsection{Participants}

At the start of the research, all children belonged to two parallel classes of the first grade of a mainstream medium-sized primary school in the center of the Netherlands. Of the 34 children in Grade 1, two children left school at the end of Grade 1 and could not be assessed further. The remaining 32 children (15 girls and 17 boys) were all evaluated three times (first, second and third grade) for all measures. Their mean age was 7;1 (years; months) in Grade 1 (range 6;4 7;6), 8;1 (7;4 - 8;6) in Grade 2 and 9;1 (8;4 - 9;6) in Grade 3. Four girls and two boys were lefthanded. All participants had normal hearing and normal or corrected-to-normal vision, were of Caucasian race and had the Dutch language as their first language.

\subsection{Procedure and Materials}

To investigate the interrelationships between developing spelling, reading and handwriting skills the children were assessed in Grades 1, 2 and 3. The first assessment took place in February/March in Grade 1, approximately 7 months after their start in Grade 1 and 3 months after the children had started practicing graphemes with joins for cursive handwriting. They were re-assessed in February/March of Grades 2 and 3.

For handwriting, a standardized 5 minutes copying task was used which provided speed and legibility scores [2,23]. The copying task was given as group assignment; the results were individually evaluated by one of the authors (I.BS). Language skills - i.e., reading and spelling achievements - were pulled out of the schoolbased, national organized Dutch follow-up system, used by schoolteachers. The scores for reading and spelling from the first school assessment (January/February) were used for the current analyses. To capture motor proficiency independently from linguistic processing, an existing loop-writing task was 
used, see: $[24,25]$. The children were tested individually by the same administrator (I.B-S) in a quiet room in the school, seated on an adjustable chair, with their feet supported and in a writing position adapted to the digitizer tablet. The task took 45 minutes of time and was also administered in February/March.

The primary school's institutional review board approved the study and each year all parents of the participants gave their informed consent and all children agreed to participate. Each child received a little present after each experimental session. Experimental procedures followed the APA guidelines for the ethical treatment of human participants.

\subsubsection{Handwriting performance}

The Concise Assessment Scale for Children's Handwriting (acronym BHK) was used to assess handwriting speed and legibility [23]. The BHK was tested as a group assignment. Their teacher administered the test, while the children were seated at their own table in the classroom, writing with their own pen in their usual handwriting style. The test consisted of copying a standard preprinted text on a plain sheet of A4 paper during 5 minutes, or five lines if the child is a very slow writer. Handwriting legibility was evaluated by assessing 13 dysgraphia features such as for example letter size, spacing, letter distortion, acute turns, corrected letterforms. Handwriting speed was measured by counting the number of letters produced in five minutes, which can be translated into deciles scores related to the child's grade. A slow writer was defined as a child in deciles $1-2$ of their norm group ( $<71$ letters for Grade 1; $<86$ for Grade 2; $<132$ for Grade 3), a typical writer as a child in deciles $3-8$, and a fast writer as a child in deciles $9-10$ (>98 letters for Grade 1; $>141$ for Grade 2; $>191$ for Grade 3). The interrater reliability of the BHK has been reported to vary between $r=.71$ and $r=.89$; intrarater reliability was $r=.87$ to $r=.94$ for Grade 2 and $r=.79$ to $r$ $=.88$ for Grade 3, while the test-retest reliability was found to vary between .51-.55 [23]. Handwriting legibility performance was not taken into account because the BHK battery does not yield handwriting quality scores for Grade 1 and cannot therefore be used to measures change between grades 1 and 2 . At the beginning of this research, the $\mathrm{BHK}$ was the most frequently used handwriting test for Dutch children. Although the norms are updated in the recently published shorter version, the BHK norms are still valid. For this research we will focus on differences in handwriting speed.

\subsubsection{Language skill measures: reading and writing}

A standardized Dutch reading test $[26,27]$ for technical reading performance $(\mathrm{AVI})$ was used to assess reading ability. The AVI reading score for each pupil is determined twice a year and is arrived at by asking the child to read out loud a number of age-appropriate sentences within a prescribed interval. The AVI score depends on the speed and accuracy of performance. The standardized Dutch spelling measure assesses spelling in 25 words or sentences, varying with age. For Grade 1 the teacher dictates single words with word illustrations on the assignment page. For Grades 2 and 3 the teacher first reads a sentence out loud then a target word is dictated and written down by the children in their assignment book. From mid-Grade 2 on, multiple-choice assignments are included. The child has to find the one misspelled word in four sentences with bold target words [28,29].

For each child the follow-up system calculates performance scores relative to 'didactical age', the latter being expressed as the total number of months in school with a maximum of 10 months per year. The raw test scores of reading and spelling are thus converted into a learning output percentage, which reflects the development of the norm group as well as the child's place within the norm group. It gives information on the reading and spelling levels and their progression in relation to the population. A learning output percentage of a $100 \%$ means that a pupil meets the learning demands of his/her grade, a higher percentage reflects that the pupil learns faster, and a lower percentage reflects he/she is a slower learner in relation to the demands of the grade. We used the learning output percentage scores for the spelling and reading measures.

\subsubsection{Loop writing performance}

Loop-writing performance was evaluated using a non-linguistic loop-writing task performed with an electronic pen (Intuos3) on a digitizer (WACOM A4 Oversize tablet), which sampled the $X-Y$ coordinates of the pen tip position at $200 \mathrm{~Hz}$. The children were asked to draw loops of different height (12, 9, 6 and $3 \mathrm{~mm}$, reflecting the gradual diminishing line width used in the school system) on sheets of paper with lines indicating the target 
heights. The task was paced by means of an acoustic signal of either 1,2 or $3 \mathrm{~Hz}$ to assess the degree to which the children were able to generate requested loop amplitudes under increasing timing constraints. The pacing signal changed sinusoidal in intensity across a clearly audible range (approximately 60-70 dB; tone pitch $330 \mathrm{~Hz}$ ). Without the influence of linguistic demands, the higher pacing frequencies challenged the children's amplitude production accuracy, which we assumed to increase the sensitivity of our assessment of the fine motor coordination required for producing handwriting. A trial consisted of six repetitions of 18 loops using the twelve amplitude-frequency combinations, which were presented at random leading to a total of 1296 loops per experiment in Grades 1, 2 and 3 (i.e., a maximum of 3888 loops per child). Before the experiment started, the children were allowed to practice the task a few times to get comfortable with the experimental procedure and task requirements. For this purpose, in Grade 1 each of the three frequencies was performed twice, using the 9 and $12 \mathrm{~mm}$ loop patterns, thus yielding 12 practice trials in Grade one. In Grades 2 and 3 each of the three frequencies was practiced twice, using only the $9 \mathrm{~mm}$ loop pattern (6 practice trials) For details see [25,29].

\subsection{Data Analysis and Statistical Procedures}

Preprocessing of the digitized loop writing movements involved linear interpolation of missing data points, $2^{\text {nd }}$-order, zero phase-lag Butterworth filtering with a cut-off frequency of 8 $\mathrm{Hz}$ and finding, by means of an automatic peakdetection algorithm, the extrema in the vertical pen-tip displacement data. The detection of extrema was visually checked, yielding a total of $1.78 \%$ trials $(n=419)$ that were rejected. Subsequently, for each loop the differences between the instructed and performed amplitude, frequency and the standard deviation of the relative phase were calculated. For an extensive description of the analysis of the kinematic data see references $[25,29]$.

Performance measures reflecting handwriting speed, reading and spelling levels, and finemotor skill were determined for each child individually. Between-subject variability within a grade was expressed in standard deviations and coefficient of variation. Between-grade performance changes were calculated by subtracting, per child, the scores obtained in Grade 1 from those measured in Grade 2 (and the scores from Grade 2 from those in Grade 3) such that for both grade differences positive scores reflected improvement in performance.

To determine the interdependencies between the investigated literacy and motor skills we choose Kendall's tau rather than Pearson or Spearman correlation coefficients, for its non-parametric properties, the absence of linear relationships between variables and the small sample under investigation [30]. The correlations between the test scores were calculated per Grade. To determine the interdependencies between the changes in the literacy and motor skills between Grades 1 and 2 and the changes of these skills between Grades 2 and 3, Kendall's tau was also determined between the difference scores between Grades 1 and 2, and the difference scores between Grades 2 and 3. To assess the developing relations between handwriting and literacy skills in slow hand writers in particular, we identified in Grade 1 slow writers according to the BHK (i.e. scoring in the $1^{\text {st }}$ or $2^{\text {nd }}$ deciles of the norm group).

Analyses were conducted in SPSS-22 with statistical significance level $\alpha=.05$.

\section{RESULTS}

The general performance of the children for the handwriting-, language- and loop-writing performance for each grade, expressed in mean, standard deviation (SD), the coefficient of variation $(\mathrm{CV})$, the minimum and maximum and confidence interval of the mean $(\mathrm{Cl})$, are shown in Table 1. Over the three grades the performance in handwriting increased. For reading and spelling the children increased their competence in reaching the requirements of their grades (the mean learning percentage for spelling decreased relatively in Grade 3, but still met the requirements for this grade), and the errors and the variability in coordination in the loop-writing task decreased (see Table 1).

The change in performance between Grades 1 and 2 and between Grades 2 and 3 for the handwriting, language and motor indices are reported separately in Table 2. For the handwriting speed and language scores a 
positive difference score reflects performance improvement, for the motor capacity scores the reverse is true because the measures concern error scores and coordination variability. The $p$ values of Table 2 test whether the means reported in the previous table, Table 1, are different. As displayed in Table 2, all literacy and motor scores improved significantly between Grades 1 and 2. The standardized effect size was large for handwriting speed $(d=2.19)$ but weaker for the other variables $(|d|$ between 0.40 and 0.69). Between Grades 2 and 3, there was a significant improvement in handwriting speed, frequency error and coordination variability, but not in reading, spelling, and amplitude error. The standardized effect size was large for handwriting speed $(\mathrm{d}=1.92)$ but not for frequency error and coordination variability $(d=-$ 0.36 and -0.57 , respectively).

The rank-order correlations (Kendal's tau) between the handwriting speed production, language and loop-writing performance measures for each grade separately are given in Table 3. In Grades 1,2 and 3 there were statistically significant positive correlations between the reading and spelling measures, $(\mathrm{T}=$ .35, .49 and .33 for Grades 1, 2 and 3; $P=.004$; .000 and .005 respectively). Reading showed a significant positive correlation with handwriting speed in Grade 1 only ( $\mathrm{T}=.37, P=.003$ ), while spelling showed a significant positive correlation with handwriting speed in the first and second grade $(\mathrm{\tau}=.36$ and $.39, \quad P=.004 ; .001$ respectively). For the motor performance domain in the loop-writing task, the error in amplitude was negatively correlated to both language measures, but only in Grade 1 (for reading $\mathrm{T}=$ .33; $P=.007$, for spelling $\mathrm{T}=-.36 ; P=.004)$. Over all three grades, the frequency errors in loopwriting performance showed a significant positive correlation with the variability of coordination in this task $(\mathrm{T}=.73, .71$ and .78 for Grades 1,2 and 3; all $P s=.000)$.

Table 1. Descriptive statistics for handwriting speed, language performance (reading and spelling) and loop-writing performance (amplitude and frequency errors and variability of coordination) differentiated for each measure for Grades 1, 2 and 3

\begin{tabular}{|c|c|c|c|c|c|c|c|c|}
\hline \multirow[t]{2}{*}{ Variable } & \multirow[t]{2}{*}{ Grade } & \multirow[t]{2}{*}{ Mean } & \multirow[t]{2}{*}{ SD } & \multirow[t]{2}{*}{ CV\% } & \multicolumn{2}{|c|}{ Range } & \multicolumn{2}{|c|}{$95 \% \mathrm{Cl}$} \\
\hline & & & & & Min & $\operatorname{Max}$ & LL & UL \\
\hline \multicolumn{9}{|l|}{ Handwriting } \\
\hline Speed (number of & 1 & 57 & 23 & .40 & 15 & 100 & 48 & 65 \\
\hline \multirow[t]{2}{*}{ letters per $5 \mathrm{~min}$ ) } & 2 & 125 & 36 & .29 & 56 & 203 & 112 & 138 \\
\hline & 3 & 200 & 50 & .25 & 133 & 357 & 182 & 218 \\
\hline \multicolumn{9}{|l|}{ Language } \\
\hline Reading & 1 & 112 & 77 & .69 & 14 & 214 & 85 & 140 \\
\hline \multirow[t]{2}{*}{ (learning percentage) } & 2 & 133 & 67 & .50 & 29 & 285 & 109 & 157 \\
\hline & 3 & 136 & 46 & .34 & 23 & 250 & 119 & 152 \\
\hline Spelling & 1 & 95 & 57 & .60 & 57 & 243 & 75 & 116 \\
\hline \multirow{2}{*}{ (learning percentage) } & 2 & 124 & 55 & .44 & 33 & 227 & 104 & 144 \\
\hline & 3 & 115 & 36 & .31 & 27 & 177 & 102 & 128 \\
\hline \multicolumn{9}{|l|}{ Loop Writing } \\
\hline Amplitude Error & 1 & 1.52 & .52 & .34 & .67 & .64 & 1.33 & 1.71 \\
\hline \multirow{2}{*}{$(\mathrm{mm})$} & 2 & 1.29 & .56 & .43 & .57 & .61 & 1.09 & 1.49 \\
\hline & 3 & 1.24 & .62 & .50 & .52 & .28 & 1.01 & 1.46 \\
\hline Frequency Error & 1 & .33 & .17 & .52 & .09 & .68 & .27 & .39 \\
\hline \multirow{2}{*}{$(\mathrm{Hz})$} & 2 & .24 & .17 & .71 & .09 & .65 & .18 & .30 \\
\hline & 3 & .21 & .13 & .62 & .05 & .53 & .16 & .25 \\
\hline \multicolumn{9}{|l|}{ Coordination } \\
\hline Variability & 1 & 67.15 & 5.69 & .08 & 50.46 & 76.14 & 65.10 & 69.21 \\
\hline \multirow{2}{*}{ (deg) } & 2 & 63.74 & 6.34 & .10 & 51.74 & 76.38 & 61.45 & 66.02 \\
\hline & 3 & 60.74 & 8.08 & .13 & 46.65 & 73.38 & 57.83 & 63.66 \\
\hline
\end{tabular}


Table 2. Changes in performance form Grade 1 to Grade 2 and from Grade 2 to Grade 3 for handwriting speed, language measures for reading and spelling and loop-writing measures for amplitude error, frequency error and variability of coordination

\begin{tabular}{|c|c|c|c|c|c|c|c|c|c|c|c|}
\hline \multirow[t]{2}{*}{ Variable } & \multirow[t]{2}{*}{ Grade } & \multirow[t]{2}{*}{ Mean } & \multirow[t]{2}{*}{ SD } & \multicolumn{2}{|c|}{ Range } & \multirow{2}{*}{$\begin{array}{l}\text { Cohen's } \\
\text { d }\end{array}$} & \multirow[t]{2}{*}{$t(31)$} & \multirow[t]{2}{*}{ 2-sided p } & \multicolumn{3}{|c|}{$95 \% \mathrm{Cl}$ of d } \\
\hline & & & & Min & Max & & & & & LL & UL \\
\hline \multicolumn{12}{|l|}{ Handwriting } \\
\hline \multirow{2}{*}{$\begin{array}{l}\text { Speed } \\
\text { (nr.let/5min) }\end{array}$} & $1-2$ & 68 & 31 & -1.0 & 137 & 2.19 & 12.41 & $<.001$ & $* *$ & 1.54 & 2.78 \\
\hline & $2-3$ & 75 & 39 & 5 & 194 & 1.92 & 10.88 & $<.001$ & $* *$ & 1.33 & 2.46 \\
\hline \multicolumn{12}{|l|}{ Language } \\
\hline \multirow{2}{*}{$\begin{array}{l}\text { Reading } \\
\text { (learning \%) }\end{array}$} & $1-2$ & 21 & 51 & -96 & 117 & 0.41 & 2.33 & .027 & * & 0.05 & 0.77 \\
\hline & $2-3$ & 3 & 44 & -87 & 131 & 0.07 & 0.39 & .702 & & -0.28 & 0.41 \\
\hline \multirow{2}{*}{$\begin{array}{l}\text { Spelling } \\
\text { (learning \%) }\end{array}$} & $1-2$ & 29 & 57 & -127 & 141 & 0.51 & 2.88 & .007 & $* \star$ & 0.14 & 0.87 \\
\hline & $2-3$ & 9 & 43 & -112 & 104 & -0.21 & -1.18 & .245 & & -0.56 & 0.14 \\
\hline \multicolumn{12}{|l|}{ Loop Writing } \\
\hline \multirow{2}{*}{$\begin{array}{l}\text { Amplitude } \\
\text { Error (mm) }\end{array}$} & $1-2$ & -.23 & .58 & -1.41 & 1.47 & -0.40 & -2.24 & .032 & * & -0.75 & -0.03 \\
\hline & $2-3$ & -.05 & .66 & -1.36 & 1.87 & -0.08 & -0.43 & .671 & & -0.42 & 0.27 \\
\hline \multirow{2}{*}{$\begin{array}{l}\text { Frequency } \\
\text { Error }(\mathrm{Hz})\end{array}$} & $1-2$ & -.09 & .14 & -.33 & .30 & -0.64 & -3.64 & $<.001$ & $* *$ & -1.02 & -0.26 \\
\hline & $2-3$ & -.04 & .11 & -.31 & .23 & -0.36 & -2.06 & .048 & * & -0.72 & 0.00 \\
\hline \multicolumn{12}{|l|}{ Coordination } \\
\hline \multirow{2}{*}{$\begin{array}{l}\text { Variability } \\
\text { (deg) }\end{array}$} & $1-2$ & -3.42 & 4.98 & -13.4 & 8.38 & -0.69 & -3.88 & $<.001$ & $* *$ & -1.07 & -0.30 \\
\hline & $2-3$ & -3.00 & 5.23 & -14.5 & 8.21 & -0.57 & -3.24 & .003 & ** & -0.94 & -0.20 \\
\hline
\end{tabular}

Table 3. Summary of correlations for scores on handwriting speed, reading learning percentage, spelling learning percentage, amplitude error, frequency error and variability of coordination for Grade 1, 2 and 3 separately

\begin{tabular}{|c|c|c|c|c|c|c|c|c|c|}
\hline & \multicolumn{3}{|c|}{ Language } & & \multicolumn{5}{|c|}{ Loopwriting } \\
\hline & Reading & & Spelling & & Amp & Error & Freq Error & Variability & \\
\hline $\begin{array}{l}\text { Grade } 1 \\
\text { Handwriting Speed }\end{array}$ & .373 & $* *$ & .356 & ** & -.159 & & -.129 & -.235 & * \\
\hline Reading learning \% & & & .353 & ** & -.329 & ** & -.175 & -.185 & \\
\hline Spelling learning \% & & & & & -.355 & ** & -.169 & -.093 & \\
\hline Amplitude Error & & & & & & & -.035 & .000 & \\
\hline $\begin{array}{l}\text { Frequency Error } \\
\text { Grade } 2\end{array}$ & & & & & & & & .729 & ** \\
\hline Handwriting Speed & .148 & & .386 & $* *$ & -.069 & & .010 & -.048 & \\
\hline Reading learning \% & & & .494 & $* *$ & -.070 & & -.050 & -.115 & \\
\hline Spelling learning \% & & & & & -.008 & & -.194 & -.258 & * \\
\hline Amplitude Error & & & & & & & -.113 & -.004 & \\
\hline Frequency Error & & & & & & & & .712 & ** \\
\hline Grade 3 & & & & & & & & & \\
\hline Handwriting Speed & .156 & & .166 & & .114 & & -.171 & -.085 & \\
\hline Reading learning \% & & & .332 & $* *$ & -.035 & & -.180 & -.189 & \\
\hline Spelling learning \% & & & & & -.204 & & -.241 & * -.207 & \\
\hline Amplitude Error & & & & & & & -.109 & .020 & \\
\hline Frequency Error & & & & & & & & .779 & ** \\
\hline
\end{tabular}


The rank-order correlations (Kendal's tau, one tailed) for the change in performance of handwriting in relation to literacy and motor skills within grade 1-2 and within grade 2-3 are given in Table 4. Within Grade 1-2 there was a weak but significant negative relationship for handwriting speed and learning percentage for reading $\mathrm{T}=-.27, P<.018$. Within Grade 2-3 there existed a weak, but significant positive relationship between handwriting speed and amplitude errors in loop writing $\mathrm{T}=.24, P<.027$.

The development of the literacy skills for children with slow handwriting speed in Grade 1 as compared to the other children is presented in Fig. 1. In Grade 1 the slow writers were those children whose handwriting speed scored in the $1^{\text {st }}$ and $2^{\text {nd }}$ deciles of the BHK as defined in the 1987 norm group. The other children's handwriting speed ranged between the $3^{\text {rd }}-10^{\text {th }}$ deciles on the BHK. Twenty-four children (75\%, 13 girls and 11 boys) proved slow writers whereas 8 children ( 4 boys and 4 girls) were not. This categorization of children on the basis of handwriting speed in Grade 1 was used to track the development of literacy and motor skills of both groups over the three years of development. Panel A (Fig. 1) shows an increasing handwriting speed over the three years, whereby the slow children in Grade 1 (straight line), remained relatively slow in Grades 2 and 3 . For the development of reading and spelling performance (panel $B$ and $C$ ) the two groups started at a different level but attained equal or nearly equal performance levels in Grade 3.

\section{DISCUSSION}

In this exploratory longitudinal study 32 children were followed in three successive years with respect to their handwriting speed, reading, spelling, and fine motor skills (loop-writing). The group means unfolded the following pattern. From Grade 1 to Grade 3 the children showed marked progress in writing speed that was fairly consistent across individuals. The improvements in reading, spelling learning performance and loop writing were less consistent.

Table 4. Summary of correlations of the changes in performance of reading, spelling (Literacy), amplitude errors, frequency errors and variability of coordination (Loop-writing) in relation to handwriting speed measures, between Grades 1-2 and between Grades 2-3, separately

\begin{tabular}{ll}
\hline Measure & Handwriting Speed \\
\hline Grade 2-1 difference & \\
Reading learning \% & -.265 \\
Spelling learning \% & -.098 \\
Amplitude Error & .00 \\
Frequency Error & .047 \\
Variability & .045 \\
Grade 3-2 difference & \\
Reading learning \% & .078 \\
Spelling learning \% & .057 \\
Amplitude Error & .241 \\
Frequency Error & .159 \\
Variability & -.051 \\
\hline
\end{tabular}

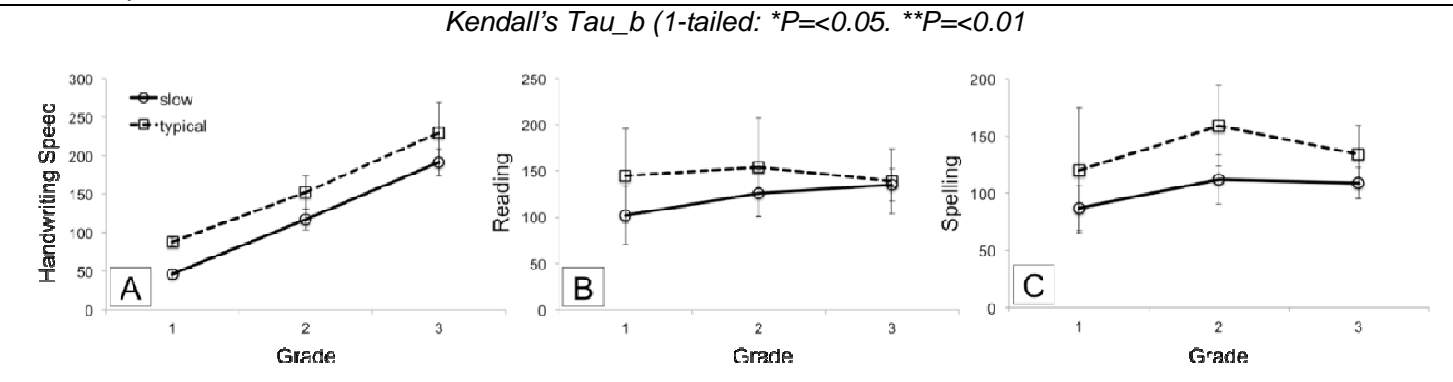

Fig. 1. Literacy and motor development as a function of handwriting speed in the first grade. A: Handwriting speed as a function of grade for hand writers who are slow (solid line) or typical (dashed line) in Grade 1 as measured by the BHK. This handwriting-speed based split of the participants is maintained in B-C. B: reading learning percentage, C: spelling learning percentage 
In Grade 1, handwriting speed had a significant positive correlation with reading, spelling, and the coordination variability dimension of loop writing. In Grade 2, handwriting speed had a significant positive correlation with spelling but not with any of the other variables. In Grade 3, handwriting speed had no significant correlations with the other measures. These results suggest that handwriting develops into an autonomous skill that in Grade 3 becomes independent of other cognitive components. Thus, while handwriting shares cognitive resources with reading and language production skills in the first grades, it depends on its own specialized resources in the third grade. These results are in line with Berninger [7] who formulated four functional language systems that are interconnected, but show an independent development [31]. Alternatively, these lower correlations in Grade 3 can be explained by assuming that in this grade, unlike in Grade 1 and 2, the children's spelling capacities start to match the difficulty of the transcription task. Furthermore, slow handwriting speed in Grade 1 not only persisted in Grades 2 and 3 , but also was indicative for a lower spelling performance in Grades 2 and 3.

The high number of children with a slow handwriting speed development in Grade 1 was remarkable. The results and interpretations of handwriting speed measurements strongly depend on the test battery used and the moment of assessing skill performance within the school year [19-21,32-34]. The fact that $75 \%$ of the children initially scored in the deciles $1-2$ might be due to the timing of our assessment, which took place in February/March, whereas the norm sample of Hamstra-Bletz [23] was tested in June. In literature the development of legibility is unambiguous, the quality of handwriting for girls is better than for boys. Differences in handwriting speed between boys and girls however, are not as clear $[1,3,20,35-38]$. In our cohort there was no difference between boys and girls for the development of handwriting speed. This finding is in agreement with Feder's research [1].

The findings in this study confirm the moderate but systematic connection that exists between reading and spelling, at least as far as they develop in the first three grades of primary school. These results are comparable to the results of the longitudinal study by Abbott [8], in which a spelling to word-reading relationship was found $[7,39]$, although the handwriting task (PAL, Alphabet Writing) that was used in Abbott's research is not the same as the transcription task used in this study. These findings underline the necessity to look not only at the motor performance side of handwriting, but also at the development of reading as well as spelling if handwriting does not develop as expected by the teacher.

There are several limitations for this exploratory developmental study. The learning conditions were not experimentally manipulated in this study. For this reason it is not possible to draw strong conclusions about causal relations. However, if the suggested explanation of the handwriting skill becoming increasingly more automatic in Grade 3 were correct, one would predict differential effects of tasks that introduce difficulties in reading or spelling. For example, writing non-words would have a larger effect in Grade 1 than in Grade 3. Furthermore, a delay or deficiency in the development of reading or spelling might either slow down development or trigger an alternative developmental path for these skills, since reading and spelling are different in sensory input $[39,40]$.

Caution is due with the interpretation of 'learning $\%$ ' used for the spelling and reading task. These scores are no direct performance scores from spelling and reading tasks, but a reflection of the progress, stability or decline of these abilities over the year, compared to the learning demands of a grade for an individual child. Thus, the nonsignificant difference between Grades 2 and 3 for spelling in Table 2 does not mean a lack of progress in their spelling performance, but rather that their progress was average. Learning percentages are useful for individual children, since they signal fluctuation in the capacity to comply with the grades performance levels.

Further research on the individual development of children concerning the relationships between handwriting skills and language development as well as growth across the grades of reading, spelling and motor skills is warranted. Differences in individual capacities and adaptability within children belonging to one grade need to be looked into in order to make solid choices for remediation. Nowadays most handwriting research is concentrated on differences between normal and dysgraphic handwriting development and kinematic features of these differences, for example as shown by Chang \& $Y u$ and others [41-43], while interactions between language and writing are covered by many authors [44-46]. However, studies that combine the underlying skills of 
handwriting development in school settings, aimed at the interactions at the level of developing skills are scarce. An exploratory study is a start to reach these goals.

\subsection{Implications for Primary Education}

For teachers and therapists, slow handwriting speed development, is often a first indication that the complex skill involving perceptual, motor and language capacities might show an unexpected delay. Children in the first years in primary school are generally not yet (fully) diagnosed for possible learning disorders. Assessment of handwriting might therefore be a good starting point for differentiating learning disorder. Since slow handwriting speed development in Grade 1 is, at least for this group and at this moment in their education a common occurrence, it presumably is not an indication of spelling or reading difficulties. In handwriting assessments the timing of assessment in first grade is essential. Depending on the school curriculum, handwriting, spelling and reading all have their different and individual developmental timespan. At the end of Grade 1, typical developing children should be able to reach acceptable handwriting speed. At the end of Grade 1 and in Grades 2 and 3 , literacy skills should be taken into account when assessing an individual child's handwriting performance, since slow handwriting speed is not prevalent in these grades and handwriting speed performance in relation to spelling and reading capacities offer a wider perspective on motor performance in the context of educational goals. Assessment of handwriting development in a school setting could be further deepened by kinematic analysis of handwriting movements using dual task measurements for perception (visually and auditory) and action (by hand), as measured in the loop-writing task used in this study. Line spacing constraints are often prescribed and incorporated in the handwriting method in the Netherlands to induce normative handwriting size. Differences in capacities to cope with speed and precision should also be taken into account when defining line spacing instructions.

The inclusion of a device for kinematic analysis of children's handwriting movements in a school setting is not unthinkable in the near future, since data analyses become more and more sophisticated and easy to achieve [47], although interpretation of the data might need a remedial team consisting of teachers and pediatric therapists.
Although legibility has not been taken into account in this study, for purposes of diagnosis and treatment it seems important to track legibility alongside speed even though legibility develops sooner than speed and both need different therapeutic approaches [3].

\section{CONCLUSION}

The interrelations between developing handwriting speed and the literacy skills reading and spelling in the first three grades of primary skills were moderate but systematic, and more important than the slowly developing fine-motor skills. Development of slower handwriting speed in Grade 1 was likely to persist in Grades 2 and 3 , which was correlated with reduced capacity to comply with the learning demands for spelling. As a basis of teachers' and therapists' judgment it is advised to assess the pupil's handwriting as well as reading and motor skills, while recognizing the fact that assessment timing might define the outcomes.

\section{COMPETING INTERESTS}

Authors have declared that no competing interests exist.

\section{REFERENCES}

1. Feder KP, Majnemer A, Bourbonnais D, Blayney M, Morin I. Handwriting performance on the ETCH-M of students in a grade one regular education program. Phys Occup Ther Pediatr. 2007;27(2):4362.

Available:http://dx.doi.org/10.1080/J006v2 7n02 04 PMid:17442654

2. Hamstra-Bletz L. Het Kinder handschrift. Ontwikkeling en Beoordeling. PhD Thesis, The Netherlands: University of Leiden. Dutch; 1993.

3. Karlsdottir R, Stefansson T. Problems in developing functional handwriting (monograph supplement 1-V94). Percept Mot Skills. 2002;94(2):623-662.

Available:http://dx.doi.org/10.2466/pms.20 02.94.2.623 PMid: 12027360

4. Overvelde A, Hulstijn W. Handwriting development in grade 2 and grade 3 primary school children with normal, at risk, or dysgraphic characteristics. Res Dev Disabil. 2011;32(2):540-548.

Available:http://dx.doi.org/10.1016/j.ridd.20 10.12.027 PMid:21269805 
5. Smits-Engelsman BCM, Niemeijer AS, Van Galen GP. Fine motor deficiencies in children diagnosed as DCD on poor grapho-motor ability. Hum Mov Sci. $2001 ; 20(1-2): 161-82$.

Available:http://dx.doi.org/10.1016/S01679457(01)00033-1

6. Smits-Engelsman BCM, Van Galen GP, Michels CGJ. De leekracht beoordeeld: Inschatting van schrijfvaardigheidsproblemen en motorische achterstand bij basisschool leerlingen (Prevalence of poor handwriting and the validity of estimation of motor proficiency and handwriting performance by teachers). Tijdschr Onderwijsres. 1995;20:1-15. Dutch.

7. Berninger VW. Development of language by hand and its connections with language by ear, mouth, and eye. Top Lang Disord. 2000;20(4):65-84.

Available:http://dx.doi.org/10.1097/000113 63-200020040-00007

8. Abbott RD, Berninger VW, Fayol M. Longitudinal relationships of levels of language in writing and between writing and reading in grades 1 to 7 . $\mathrm{J}$ Educ Psychol. 2010;102(2):281-98.

Available:http://dx.doi.org/10.1037/a00193 $\underline{18}$

9. Berninger VW, Abbott RD, Jones J, Wolf BJ, Anderson-Youngstrom M, Shimade S, et al. Early development of language by hand: Composing, reading, listening, and speaking connections; three letter-writing modes; and fast mapping in spelling. Dev Neuropsychol. 2006;29(1):61-92.

Available:http://dx.doi.org/10.1207/s15326 942dn2901 5. PMid:16390289

10. Berninger V, Fuller F, Whitaker D. A process model of writing development across the life span. Educ Psychol Rev. 1996;8(3):193-218.

Available:http://dx.doi.org/10.1007/BF0146 4073

11. Flower L, Hayes JR. A cognitive process theory of writing. College Composition and Communication. 1981;32:365-387.

Available:http://dx.doi.org/10.2307/356600

12. James $\mathrm{KH}$, Gauthier I. Letter processing automatically recruits a sensory-motor brain network. Neuropsychologia. 2006; 44(14):2937-2949.

Available:http://dx.doi.org/10.1016/j.neurop sychologia.2006.06.026 PMid:16920164

13. Jones D, Christensen CA. Relationships between automaticity in handwriting and students' ability to generate written text. J Educ Psychol. 1999;91(1):44-49.

Available:http://dx.doi.org/10.1037/00220663.91.1.44

14. Rijlaarsdam G, Van den Bergh $H$. Writing process theory: A functional dynamic approach. In: MacArthur CA, Graham S, Fitzgerald J. editors. Writing Research (pp. 41-53). New York: Guildford Press; 2006.

15. Childress A. Understanding writing problems in young children: Contributions of cognitive skills to the development of written expression, Dissertation University of North Carolina, Chapel Hill; 2011.

16. Tolchinsky $L$. The emergence of writing. In: MacArthur CA, Graham S, Fitzgerald J. editors. Writing Research (pp. 83-95). New York: Guildford Press; 2006.

17. Juel C, Griffith PL, Gough PB. Acquisition of literacy: A longitudinal study of children in first and second grade. J Educ Psychol. 1986;78(4):243-255.

Available:http://dx.doi.org/10.1037/00220663.78.4.243

18. Berninger VW, Yates C, Cartwright A, Rutberg J, Remy E, Abbott R. Lower-level developmental skills in beginning writing. Read Writ. 1992;4(3):257-280.

Available:http://dx.doi.org/10.1007/BF0102 $\underline{7151}$

19. Van Galen GP. Handwriting: Issues for a psychomotor theory. Hum Mov Sci. 1991; 10(2):165-191.

Available:http://dx.doi.org/10.1016/01679457(91)90003-G

20. Graham S, Berninger V, Weintraub N, Schafer W. Development of handwriting speed and legibility in Grades 1-9. J Educ Res. 1998;92(1):42-52.

Available:http://dx.doi.org/10.1080/002206 79809597574

21. Hamstra-Bletz L, Blöte AW. Development of handwriting in primary school: A longitudinal study. Percept Mot Skills. 1990;70:759-770.

22. Bourdin B, Fayol M. Is graphic activity cognitively costly? A developmental approach. Read Writ. 2000;13(3-4);183196.

Available:http://dx.doi.org/10.1023/A:1026 458102685

23. Hamstra-Bletz L, De Bie J, Den Brinker BPLM. Beknopte beoordelingsmethode voor kinderhandschriften: experimentele versie (Concise evaluation-scale for children's handwriting: Experimental 
version). Swetz \& Zeitlinger, Lisse, The Netherlands; 1987. Dutch.

24. Meulenbroek RGJ, Thomassen AJWM, Van Lieshout HPM, Swinnen SP. The stability of pen-joint and interjoint coordination in loop writing. Acta Psychol (Amst). 1998;100(1):55-70.

Available:http://dx.doi.org/10.1016/S0001$\underline{6918(98) 00025-0}$

25. Bosga-Stork IM, Bosga J, Meulenbroek RGJ. Intentional control and biomechanical exploitation in preparatory handwriting. Hum Mov Sci. 2011;30(4):687-697.

Available:http://dx.doi.org/10.1016/j.humov 2010.06.007 PMid:21256611

26. Visser J, Van Laarhoven A, Ter Beek A. AVi-toetspakket-, $3^{e}$ herziene versie [AVI test package, third revision]. Den Bosch: KPC; 1996. Dutch.

Available:http://www.prodiagnostiek.be/.../ Diagnostisch\%20materiaal AVI\%20toets\% 20l... (Retrieved April 1, 2015)

27. Jongen I, Krom R, Van Onna M, Verhelst $\mathrm{N}$. Wetenschappelijke Verantwoording van de toetsen Technisch lezen voor groep 3 tot en met 5 uit het LOVS. CITO, Arnhem; 2011. Dutch.

Available:http://www.toetswijzer.nl/html/tg/ 15.pdf (Retrieved April 1, 2015)

28. Wijs de A, Kamphuis F, Kleintjes F, Tomesen M. Wetenschappelijke verantwoording bij de toetsen Spelling. Arnhem: Cito; 2010. Dutch.

Available:http://www.toetswijzer.nl/html/tg/ 16.pdf (Retrieved April 1, 2015)

29. Bosga-Stork IM, Bosga J, Meulenbroek RG. Developing movement efficiency between 7 and 9 years of age. Motor control. 2014;18(1):1-17.

Available:http://dx.doi.org/10.1123/mc.201 2-0087 PMid:24496875

30. Ma Y. On inference for Kendall's $\mathrm{T}$ within a longitudinal data setting. J Appl Stat. 2012; 39(11):2441-2452.

Available:http://dx.doi.org/10.1080/026647 63.2012.712954 PMid:23554542

PMCid:PMC3611981

31. Berninger VW, Abbott RD, Abbott SP, Graham S, Richards T. Writing and reading connections between language by hand and language by eye. J Learn Disabil. 2002;35(1):39-56.

Available:http://dx.doi.org/10.1177/002221 940203500104 PMid:15490899
32. Mojet JW. Developing handwriting skill. In: Wann J, Wing AM, Søvik N. editors. The Development of Graphic Skills (pp. 53-75). London: Academic Press; 1991.

33. Van Waelvelde $H$, Hellinckx $T$, Peersman W, Smits-Engelsman BC. SOS: A screening instrument to identify children with handwriting impairments. Phys Occup Ther Pediatr. 2012;32(2):306-319.

Available:http://dx.doi.org/10.3109/019426 38.2012.678971

34. Ziviani J, Watson-Will A. Writing speed and legibility of 7-14 - year - old school students using modern cursive script. Aust Occup Ther J. 1998;45(2):59-64.

Available:http://dx.doi.org/10.1111/j.14401630.1998.tb00783.x

35. Berninger VW, Fuller F. Gender differences in orthographic, verbal, and compositional fluency: Implications for assessing writing disabilities in primary grade children. J Sch Psychol. 1993; 30(4):363-382.

Available:http://dx.doi.org/10.1016/00224405(92)90004-O

36. Graham S, Struck M, Santoro J, Berninger VW. Dimensions of good and poor handwriting legibility in first and second graders: Motor programs, visual-spatial arrangement, and letter formation parameter setting. Develop Neuropsych 2006;29(1):43-60.

Available:http://dx.doi.org/10.1207/s15326 942dn2901 4 PMid:16390288

37. Vlachos F, Bonoti $F$. Explaining age and sex differences in children's handwriting: A neurobiological approach. Eur J Dev Psychol. 2006;3(2):113-123.

Available:http://dx.doi.org/10.1080/174056 $\underline{20500371455}$

38. Medwell J, Wray D. Handwriting-A forgotten language skill? Lang Educ. 2008; 22(1):34-47.

Available:http://dx.doi.org/10.2167/le722.0

39. Bosman AMT, Van Orden GC. Why spelling is more difficult than reading. In: Perfetti CA, Rieben L, Fayol M, editors. Learning to spell: Research, theory, and practice across languages (pp. 173-194). Hillsdale, $\mathrm{NJ}$ : Lawrence Erlbaum Associates; 1997.

40. Bosman AMT, Van Olden GC. Het fonologisch coherentiemodel voor lezen en spellen. Pedagogische Studiën. 2003;80: 391-306.

41. Chang SH, Yu NY. Handwriting movement 
analyses comparing first and second graders with normal or dysgraphic characteristics. Res Dev Disabil. 2013;34(9):24-2441.

Available:http://dx.doi.org/10.1016/j.ridd.20 $\underline{13.02 .028}$

42. Khalid PI, Yunus J, Adnan R. Extraction of dynamic features from hand drawn data for the identification of children with handwriting difficulty. Res Dev Disabil. 2010;31(1):256-262.

Available:http://dx.doi.org/10.1016/j.ridd.20 $\underline{09.09 .009}$

43. Kushki A, Schwellnus H, llyas F, Chau T. Changes in kinetics and kinematics of handwriting during a prolonged writing task in children with and without dysgraphia. Research in Developmental Disabilities, 2011;32(3):1058-1064.

Available:http://dx.doi.org/10.1016/j.ridd.20 11.01 .026

44. Kandel S, Perret C. How does the interaction between spelling and motor processes build up during writing acquisition? Cognition. 2015;136:325-336. Available:http://dx.doi.org/10.1016/i.cogniti on.2014.11.014

45. Afonso O, Alvarez CJ. Phonological effects in handwriting production: Evidence from the implicit priming paradigm. J Exp Psych: Learn Mem Cogn. 2011;37(6):1474-1483.

46. Pontart V, Bidet-Ildei C, Lambert E, Morisset $\mathrm{P}$, Flouret L, Alamargot D. Influence of handwriting skills during spelling in primary and lower secondary grades. Front Psychol, 2013; 4.

Available:http://dx.doi.org/10.3389/fpsyg.2 $\underline{013.00818}$

47. Accardo A, Chiap A, Borean M, Bravar L, Zoia S, Carrozzi M. et al. A device for quantitative kinematic analysis of children's handwriting movements. In: 11th Mediterranean Conference on Medical and Biomedical Engineering and Computing (pp. 445-448). Springer Berlin Heidelberg; 2007.

Available:http://dx.doi.org/10.1007/978-3540-73044-6 114

(c) 2016 Bosga-Stork et al.; This is an Open Access article distributed under the terms of the Creative Commons Attribution License (http://creativecommons.org/licenses/by/4.0), which permits unrestricted use, distribution, and reproduction in any medium, provided the original work is properly cited. 